\title{
ISRM Suggested Method for the Determination of Mode II Fracture Toughness
}

\author{
Tobias Backers · Ove Stephansson
}

Published online: 3 July 2012

(C) Springer-Verlag 2012

\section{Introduction}

Fracture is a failure mechanism of brittle materials that is of great importance for the performance of structures. Rapid and violent failures of large-scale geotechnical, mining or civil engineering structures cause significant safety hazards, material damage, and interruption to or even cessation of mining or building activities. Ability to recognise pre-failure rock mass behaviour may result in predicting or averting the potential for geotechnical and geological failures (Szwedzicki 2003). Rock fracture mechanics is one approach to resolve this task.

Rock fracture mechanics can be employed not only to improve safety, but also to enhance the performance and profitability of rock engineering structures. Examples are the geological disposal of radioactive waste, terrestrial sequestration of carbon dioxide to ease prejudicial effects on the environment, efficient underground storage of oil, gas or air, enhanced recovery of hydrocarbons, geothermal energy extraction, and underground constructions at increasing overburden pressure for infrastructure or transport. For these geomechanical applications the stress states

Please send all written comments on these ISRM Suggested Methods to Prof R. Ulusay, President of the ISRM Commission on Testing Methods, Hacettepe University, Geological Engineering Department, 06800 Beytepe, Ankara, Turkey at resat@hacettepe.edu.tr.

T. Backers $(\bowtie) \cdot$ O. Stephansson geomecon GmbH, August-Bebel-Strasse 27, 14482 Potsdam, Germany

e-mail: tobias.backers@geomecon.de

O. Stephansson

Helmholtz-Zentrum Potsdam GFZ German Research Centre

for Geosciences, Telegrafenberg, 14473 Potsdam, Germany are mostly compressive, therefore, shearing is an important failure mechanism in rock materials.

The stress and displacement field around a crack tip during shearing results from the application of uniform shear loadings at infinity. In this so-called Mode II loading in fracture mechanics, the crack faces slide relative to each other and displacements of the crack surfaces are in the crack plane and perpendicular to the crack front. The crack initiation takes place when the crack tip stress intensity factor $K_{\mathrm{II}}$ reaches a critical value, called the Mode II plain strain fracture toughness $K_{\text {IIC }}$. The value of $K_{\text {II }}$ depends on the external loading, the geometry of the specimen and crack dimension. The fracture toughness $K_{\text {IIC }}$, sometimes called critical stress intensity factor, is a material parameter depending on the type of rock material and its physical boundary conditions, such as confining pressure and temperature.

Whittaker et al. (1992) have presented an overview of different methods for determination of Mode II fracture toughness. Some more recent methods have been proposed by e.g. Chang et al. (2002), Hakami and Stephansson (1990), Ko and Kemeny (2006), Rao et al. (2003). Only Rao et al. (2003) performed experiments on Short Beam Compression specimens with application of confining pressure that is independent of the vertical load, but the method is under discussion as it frequently delivers $K_{\text {IC }}>K_{\text {IIC }}$ (Whittaker et al. 1992; Watkins and Liu 1985).

The important influence of confining pressure on Mode II fracture toughness can only be determined by methods that can independently apply a normal load to the fracture plane. It has been stated by several researchers that under conditions of overall compression Mode II fracture, propagation is most likely (Melin 1986; Lawn 1993). This was experimentally confirmed by Bobet and Einstein (1998) who demonstrated that macroscopic wing fractures (Mode I) can 
be suppressed by applying confining pressure, i.e. normal stress. Confining pressure had to be applicable to the specimen to be able to suppress macroscopic tensile fracturing. The Punch-Through Shear with Confining Pressure (PTS/CP) experiment (Backers 2005; Backers et al. 2002a, b, 2004) allows measuring $K_{\text {IIC }}$ at different confining pressures. A modified version of PTS/CP test of rectangular samples under biaxial loading was presented by Lee (2007).

In Mode I loading the crack is subjected to a normal stress, the crack surfaces separate symmetrically and the crack front propagates in direction of the crack plane. Three ISRM Suggested Methods for determining Mode I fracture toughness $K$ have been presented (Ouchterlony 1988; Fowell et al. 1995). Fracturing in rock structures commonly occurs under mixed mode I-II loading where crack faces undergo both opening and sliding displacements and where pure Mode I stress and pure Mode II stress intensity are the limiting cases of mixed mode I-II loading. To solve common rock engineering problems with a fracture mechanics approach both fracture toughnesses $K_{\mathrm{IC}}$ and $K_{\mathrm{IIC}}$ are needed.

The suggested method for $K_{\text {IIC }}$ fracture toughness determination makes use of the PTS/CP experiment, where specimens from $K_{\mathrm{IC}}$ testing (Chevron Bend test Ouchterlony 1988) can be used to obtain fracture toughness data for both Mode I and Mode II analysis.

It may be discussed if the concept of mode of fracturing is applicable to rock material. Rock is, in general, a multicomponent material. Hence, when a fracture propagates through the material, it may not follow a straight trace but is influenced by grain boundaries, cracks, flaws and other discontinuities. From a mathematical point of view, in which the concept of the mode of fracturing was developed, a pure mode of fracture can only be achieved if the fracture propagates in a straight continuous plane within a given homogeneous stress field. Therefore, any deviation of the propagation direction of the fracture within the applied stress field introduces some mixed mode kind of fracturing.

Moreover, the fracture follows the given fabric and the fabric itself will introduce stress fluctuations that superimposes to the applied stress field (Dyskin 1999). In addition, the fracture generated will itself introduce cracks in its surrounding and build up a zone of mixed mode microcracking, the so-called fracture process zone. Hence, for a granular material the differentiation into the mode of fracturing is not possible on the microscale.

From analysis of acoustic emission recording in laboratory experiments it has been clearly shown that at Mode I and Mode II loading conditions, where the macroscopic fracture follows the direction of Mode I and Mode II, respectively, the micromechanical breakdown involves both tensile as well as shear cracking (e.g. Backers et al.
2005; Stanchits et al. 2003). Therefore, neither under pure Mode I nor Mode II loading conditions is the crack propagation pure tensile or pure shear; fracturing in rock material which always involves a mixed mode on the microscale.

In the context of laboratory based fracture toughness testing the mode of fracturing is here understood from a macroscopic point of view, at which the fracture propagation is in the direction of Mode I or Mode II. Further, as fracture toughness depends on boundary conditions, the term material property is not applicable.

\section{Scope}

The laboratory experiment is intended to directly measure the Mode II (in-plane shear) fracture toughness of rock material. The geometry of the test specimen is designed to use standard core material (NX size or $50 \mathrm{~mm}$ diameter) and to deploy the remaining halves from Mode I (tensile) fracture toughness testing by the Chevron Bend method [ISRM Suggested Method (Ouchterlony 1988)]. The experimental set-up allows the Mode II fracture toughness to be measured at different levels of confining pressure. The test is called the PTS/CP experiment.

\section{Specimen Preparation}

1. For any specimen preparation treatment appropriate high precision (preferably diamond stud) tools should be used. During specimen preparation, caution has to be taken to limit the micromechanical damage of the specimen. Micromechanical damage may influence the fracture propagation and cause reduced magnitude of fracture toughness. Cautious specimen preparation should involve slow drilling, cutting and grinding operations to limit vibrations and heat generation. If no cooling agent can be used in the process of specimen preparation, special caution has to be taken to limit the temperature increase due to specimen preparation.

2. The specimens should be right circular cylinders having a height $L$ to diameter $D$ ratio of $1: 1$ and a diameter $D$ equal to $50 \mathrm{~mm}$ (Fig. 1). The end surfaces should be flat to $0.01 \mathrm{~mm}$ and shall not depart from perpendicularity to the longitudinal axis of the specimen by more than $0.5^{\circ}$.

3. The mantle surface of the specimen cylinder should be smooth, free of abrupt irregularities and straight to within $0.5 \mathrm{~mm}$ over the full length of the specimen. Such irregularities might act as stress concentrators.

4. A circular notch of diameter ID $=0.5 D=25 \pm 0.2 \mathrm{~mm}$ and depth $a=0.1 D=5 \pm 0.2 \mathrm{~mm}$ is to be inserted into 

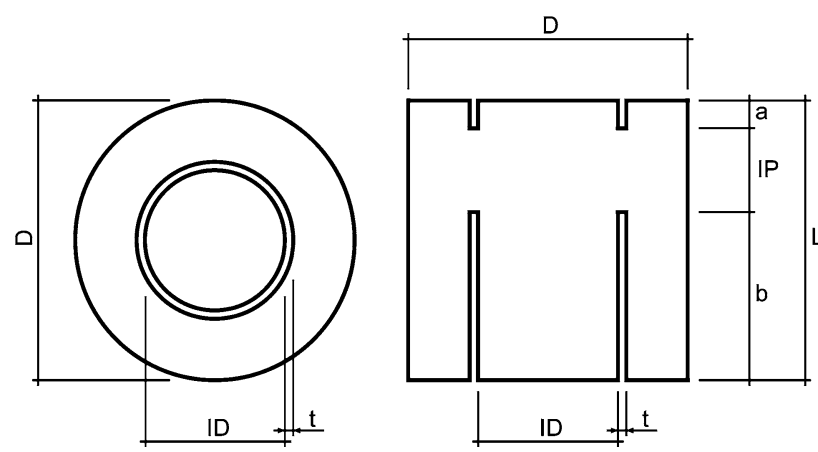

Fig. 1 Specimen geometry and dimensions of the Punch-Through Shear with Confining Pressure experiment

one end surface of the cylindrical specimen and a circular notch of diameter ID $=0.5 D=25 \pm 0.2 \mathrm{~mm}$ and depth $b=0.6 D=30 \pm 0.2 \mathrm{~mm}$ shall be manufactured into the other end surface (Fig. 1). Hence, the intact rock portion is of length IP $=L-a-b=15 \mathrm{~mm}$. The axis of the circular notches has to be aligned with the cylinder axis of the specimen. The sinking of the notches may be performed preferably by a computerised numerical control (CNC) milling machine or alternatively an appropriate hollow drill bit. The width of the notches shall be $t=1.5 \pm 0.2 \mathrm{~mm}$. The bottom of the notches should have a small curvature.

5. The dimensions of the specimen should be measured to the nearest $0.1 \mathrm{~mm}$. The specimen diameter should be measured by averaging two diameters measured at right angles at at-least two levels. The notch depths should be reported by averaging three measurements at angles of $120^{\circ}$. The specimen height should be determined by averaging three measurements at angles of $120^{\circ}$.

6. The specimen should be stored after specimen preparation for an appropriate time interval at sufficient conditions to achieve the desired moisture condition and history. The conditions of storage, moisture adjustment or drying shall be reported.

7. The minimum information on each specimen shall include dimensions, specimen preparation routines, special observations made during specimen preparation, moisture content, and macroscopic description of the surface.

\section{Experimental Set-Up}

1. The specimen is placed on top of a bottom support that has a central cut out $\mathrm{CO}$ of diameter $I D+2 t<$ $C O<I D+5 \mathrm{~mm}$ and depth $\mathrm{CD} \approx 0.1 D$ (Fig. 2).

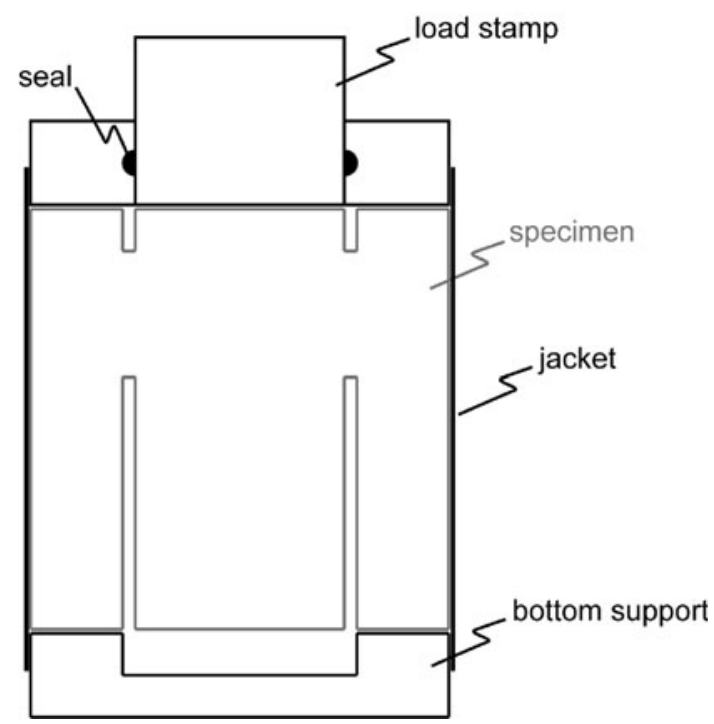

Fig. 2 Principle set-up of the Punch-Through Shear with Confining Pressure experiment

The specimen end surface with the notch of length $b$ faces downwards.

2. A load stamp assembly is placed on top of the specimen that should contain a load piston of diameter $\mathrm{LO}=\mathrm{ID}$ and shall provide a sealing of the specimen from a possible confining pressure liquid (Fig. 2).

3. The whole assembly may be covered by a jacket that seals the specimen from the confining pressure medium.

4. The assembly consisting of specimen, loading devices and jacket is placed into a loading frame of sufficient capacity and equipped with a system to apply a confining pressure that can be independently controlled. The load piston of the system should be travelled into contact with the load stamp of the installed assembly; no axial load should be applied at this stage. Thereafter, the confining pressure system should be filled with confining pressure medium.

No guidelines on how to insert the specimen assembly into the loading frame or confining pressure device are given in detail, as very different systems are available. It must be assured that the workflow can be followed with the used loading equipment.

\section{Testing Procedure}

1. The minimum information collected during experiment is the applied confining pressure $P_{\mathrm{C}}$ and peak load $F_{\max }$. However, it is advisable to continuously record the axial deformation $\delta$ (accuracy $\Delta \delta=0.001 \mathrm{~mm}$ ), the axial load $F_{\text {ax }}$ (accuracy $\Delta F_{\text {ax }}=0.05 \mathrm{kN}$ ) and the confining 
pressure (accuracy $\Delta P_{\mathrm{C}}=0.05 \mathrm{MPa}$ ) during the experiment. The rate of data acquisition should be appropriate to detect the maximum load achieved; a rate of four data sets per second (s) may be found sufficient for the suggested axial displacement rate.

2. A small pre-load $F_{\text {pre }}$ is applied to the experimental set-up. The pre-load $F_{\text {pre }}$ should be large enough to firmly stabilise the assembly, but sufficiently small as to not introduce any damage to the specimen (Fig. 3a).

3. The confining pressure $P_{\mathrm{C}}$ is applied subsequently (Fig. 3b). The confining pressure will act on the mantle surface and on the top surface of the specimen. On reaching the desired level of confining pressure, $P_{\mathrm{C}}$ should be kept constant. A servo-controlled system is recommended.

4. The axial displacement is increased at a constant rate of $\mathrm{d} \delta=0.2 \mathrm{~mm} / \mathrm{min} \quad\left(3.3 \times 10^{-6} \mathrm{~m} / \mathrm{s}\right) \quad$ (Fig. $\left.3 \mathrm{c}\right)$ resulting in an increase of the axial load. The other boundary conditions are kept constant.

5. At peak load a fracture propagates between the notches (Fig. 3d). The experiment may be terminated after driving the test to the post-peak.

6. The number of specimens per sample tested should be determined by practical considerations, but a minimum of five specimens is recommended. A sample in the sense of experiments consists of all specimens tested at the same boundary conditions.
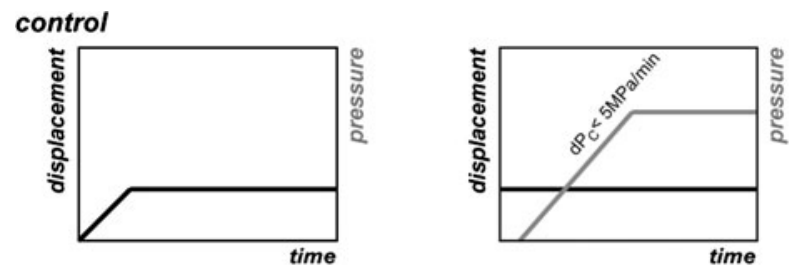

(a)
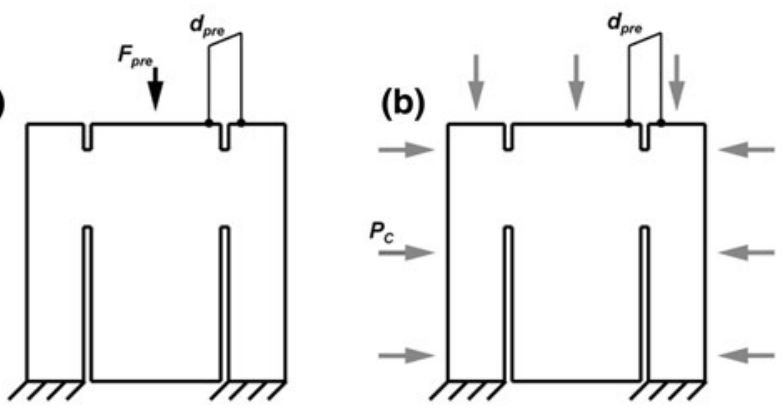

response
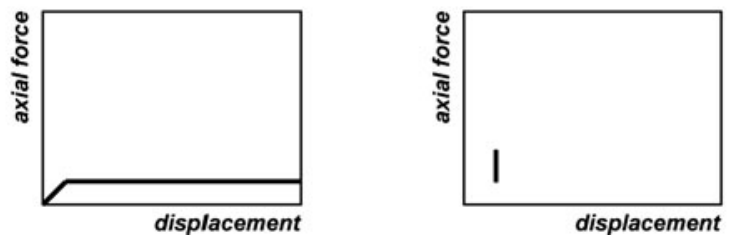

\section{Calculations}

The Mode II fracture toughness may be evaluated from the peak load $F_{\text {max }}$ achieved during testing by

$K_{\text {IIC }}=7.74 \times 10^{-2} F_{\max }-1.80 \times 10^{-3} P_{\mathrm{C}}$,

where $K_{\mathrm{IIC}}$ is in $\mathrm{MPa} \sqrt{\mathrm{m}}, F_{\max }$ is given in $\mathrm{kN}$, and $\mathrm{P}_{\mathrm{C}}$ is given in $\mathrm{MPa}$. The formula is valid for the suggested geometry only, i.e., if $L=D=50 \mathrm{~mm}$, ID $=25 \mathrm{~mm}$, $a=5 \mathrm{~mm}$ and $b=30 \mathrm{~mm}$.

\section{Reporting of Results}

The report of each experiment should at least include the following:

1. Source of specimen as precisely as possible; location and orientation.

2. Lithological description of the rock type including grain size.

3. Details of the methods used for specimen preparation, dimensions of the prepared specimen, special observations made during specimen preparation, and macroscopic description of the specimen surface.

4. Orientation of the loading axis with respect to the specimen anisotropy, bedding planes, etc.
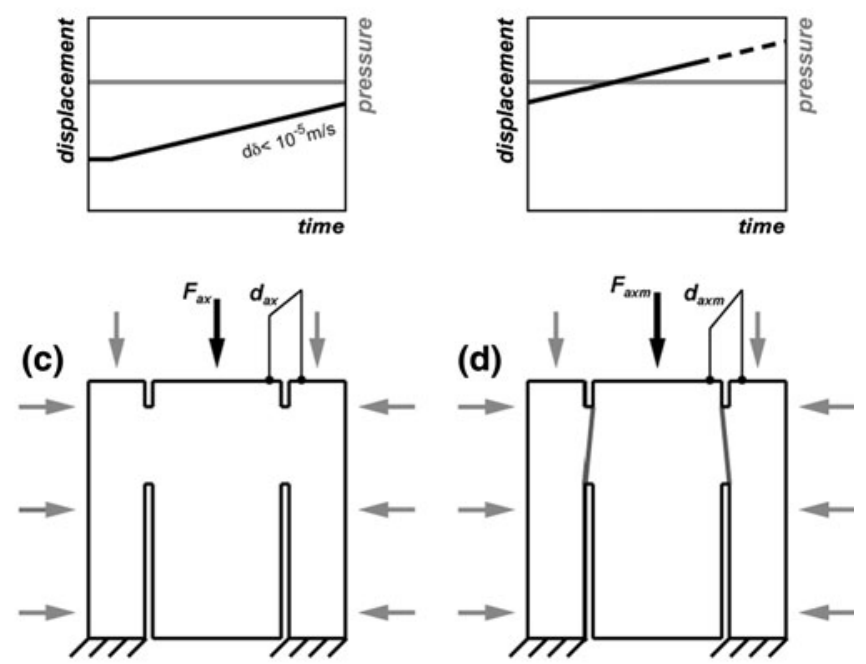

Fig. 3 Loading scheme and response of the Punch-Through Shear with Confining Pressure PTS/CP experiment

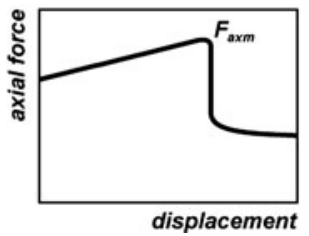


5. History and environment of test specimen storage or treatment (temperature, drying, saturation, etc.).

6. Specimen condition at time of test (saturation degree, fluid/gas content, temperature, etc.).

7. Details of experiment including history, confining pressure, loading rate, etc.

8. A record of the peak load.

9. Individual test plots showing confining pressure, axial stress and axial displacement vs. time. If there is major stress drops during loading, the test should be considered invalid.

10. The calculated value of the Mode II fracture toughness; if known, along with the Mode I fracture toughness and the ratio of $K_{\mathrm{IIC}} / K_{\mathrm{IC}}$.

11. Description of the specimen after testing, especially description of the macroscopic visible fractures. If there are fractures other than the vertical connection of the notches on stopping the test at peak load, the test may be discarded.

The report of a series of samples should contain the following:

12. The average value of each sample of experiments including a representative measure of the scatter.

13. A plot showing the Mode II fracture toughness of each sample as a function of confining pressure.

14. The ratio of $K_{\mathrm{IIC}} / K_{\mathrm{IC}}$ if the Mode I fracture toughness was determined, e.g. by the Chevron Bend experiment [ISRM Suggested Method (Ouchterlony 1988)].

\section{Typical Values}

Table 1 gives some examples of Mode I and Mode II fracture toughness values for different rocks. The Mode I fracture toughness was determined using the ISRM Suggested Method, Chevron Bend Method (Ouchterlony 1988) and the Mode II fracture toughness was determined by to the above procedure.

\section{Notes and Recommendations}

The following notes and recommendations shall support and explain the details of the suggested method. For further details on the reported results and information, please refer to the given references.

\subsection{Evaluation Procedure}

It is suggested that $K_{\text {IIC }}$ is estimated by a technique based on a displacement extrapolation technique (DET) as frequently used in literature, e.g. Lim et al. (1993). The displacement formulations are based on Irwin's crack tip displacement equations (Whittaker et al. 1992). In Cartesian coordinates, the displacements are given by

$$
\begin{aligned}
u= & \frac{K_{\mathrm{I}}}{4 G} \sqrt{\frac{r}{2 \pi}\left[(2 k-1) \cos \frac{\theta}{2}-\cos \frac{3 \theta}{2}\right]} \\
& +\frac{K_{\mathrm{II}}}{4 G} \sqrt{\frac{r}{2 \pi}\left[(2 k+3) \sin \frac{\theta}{2}+\sin \frac{3 \theta}{2}\right]}
\end{aligned}
$$

$$
\begin{aligned}
V= & \frac{K_{\mathrm{I}}}{4 G} \sqrt{\frac{r}{2 \pi}\left[(2 k+1) \sin \frac{\theta}{2}-\sin \frac{3 \theta}{2}\right]} \\
& +\frac{K_{\mathrm{II}}}{4 G} \sqrt{\frac{r}{2 \pi}\left[-(2 k-3) \cos \frac{\theta}{2}-\cos \frac{3 \theta}{2}\right]},
\end{aligned}
$$

where $u$ is the displacement in shear direction, $v$ is the displacement perpendicular to $u, G$ is the shear modulus, $k=3-4 v$, with $v$ being Poisson's ratio, $r$ is the distance from the crack tip, and $\theta$ is the angle from the shear direction. In the case of $\theta= \pm 180^{\circ}$, i.e. on the notch faces, Eqs. (2) and (3) become

$u=\frac{K_{\mathrm{II}}}{4 G} \sqrt{\frac{r}{2 \pi}[2 k+2]}$

$v=\frac{\mathrm{K}_{\mathrm{I}}}{4 G} \sqrt{\frac{r}{2 \pi}[2 k+2]}$.

Thus, $K_{\mathrm{I}}$ and $K_{\mathrm{II}}$ can be determined separately by the $x$ - and $y$-direction displacements. In the case of $K_{\mathrm{II}}, u$ is measured at the nodal points of the upper and lower notch faces, i.e. $\theta= \pm 180^{\circ}$, thus

$$
\begin{aligned}
& u_{i}^{+}=\frac{K_{\mathrm{II}}^{i}}{2 G} \sqrt{\frac{r_{i}}{2 \pi}[k+1]}, \quad \text { at } \theta=+180^{\circ} \\
& u_{i}^{-}=\frac{K_{\mathrm{II}}^{i}}{2 G} \sqrt{\frac{r_{i}}{2 \pi}[k+1]}, \quad \text { at } \theta=-180^{\circ} .
\end{aligned}
$$

The relative $y$-direction displacement of the corresponding nodes is

$\Delta u=u_{i}^{+}-u_{i}^{-}=\frac{K_{\mathrm{II}}^{i}}{G} \sqrt{\frac{r_{i}}{2 \pi}}[k+1]$

and consequently $K_{\text {II }}^{i}$ is defined by

$K_{\mathrm{II}}^{i}=\frac{G}{k+1} \sqrt{\frac{2 \pi}{r_{i}}} \Delta U_{i}$.

The $K_{\mathrm{II}}^{i}$ at given boundary stresses for different $r_{i}$ are determined and plotted as functions of the distance from the notch tip. For the linear part of that function, a linear regression extrapolates $K_{\mathrm{II}}^{i}$ to the notch tip, i.e. $r=0$ and $K_{\mathrm{II}}^{i *}$.

For the suggested geometry, the corresponding relations are determined on the bottom notch. The influence of axial loading, $\sigma_{\mathrm{A}}$, and confining pressure, $P_{\mathrm{C}}$, are evaluated (Fig. 4). 
Table 1 Values for Mode I and Mode II fracture toughness of various rocks

\begin{tabular}{|c|c|c|c|c|c|}
\hline \multicolumn{2}{|l|}{ Rock } & \multirow{2}{*}{$\frac{K_{\mathrm{IC}}}{3.8}$} & \multirow{2}{*}{$\frac{K_{\mathrm{IIC}}(\text { low } \mathrm{P})}{4.7}$} & \multirow{2}{*}{$\frac{K_{\mathrm{IIC}}(\text { high P) }}{11.5}$} & \multirow{2}{*}{$\frac{K_{\mathrm{IIC}} / K_{\mathrm{IC}}}{1.2 / 3.0}$} \\
\hline Ävrö granite, medium grained & Sweden & & & & \\
\hline Aue granite, coarse grained & Germany & 1.6 & 4.2 & 10.5 & $2.6 / 6.6$ \\
\hline Mizunami granite, medium grained & Japan & 2.4 & 4.2 & 10.9 & $1.5 / 3.8$ \\
\hline Seoul granite, finegrained & Korea & 1.6 & 4.0 & - & $2.5 /-$ \\
\hline Carrara marble & Italy & 2.4 & 3.1 & 6.7 & $1.3 / 2.8$ \\
\hline Flechtingen sandstone, finegrained & Germany & 1.2 & 2.1 & 5.3 & $1.8 / 4.4$ \\
\hline Bentheim sandstone, finegrained & Germany & 0.9 & - & - & $-1-$ \\
\hline Ruedersdorf limestone, mudstone & Germany & 1.1 & 3.1 & 4.2 & $2.8 / 3.8$ \\
\hline
\end{tabular}

Fig. 4 Displacement extrapolation technique. The displacements for the calculation of $K_{\mathrm{II}}^{i}$ were determined by 2D FEM using the standard PTS/CP geometry. (top left) from a $K_{\mathrm{II}}^{i}$ versus $r_{i}$ plot the curve is extrapolated to the $K_{\mathrm{II}}^{i}$ axis providing a linear correlation between axial stress $\sigma_{\mathrm{A}}$ and axis intercept $K_{\mathrm{II}}^{i *}$ (top right). (bottom) The same procedure provides a correlation between confining pressure $\mathrm{P}$ and $\left.K_{\mathrm{II}}^{\mathrm{i}}\right)$
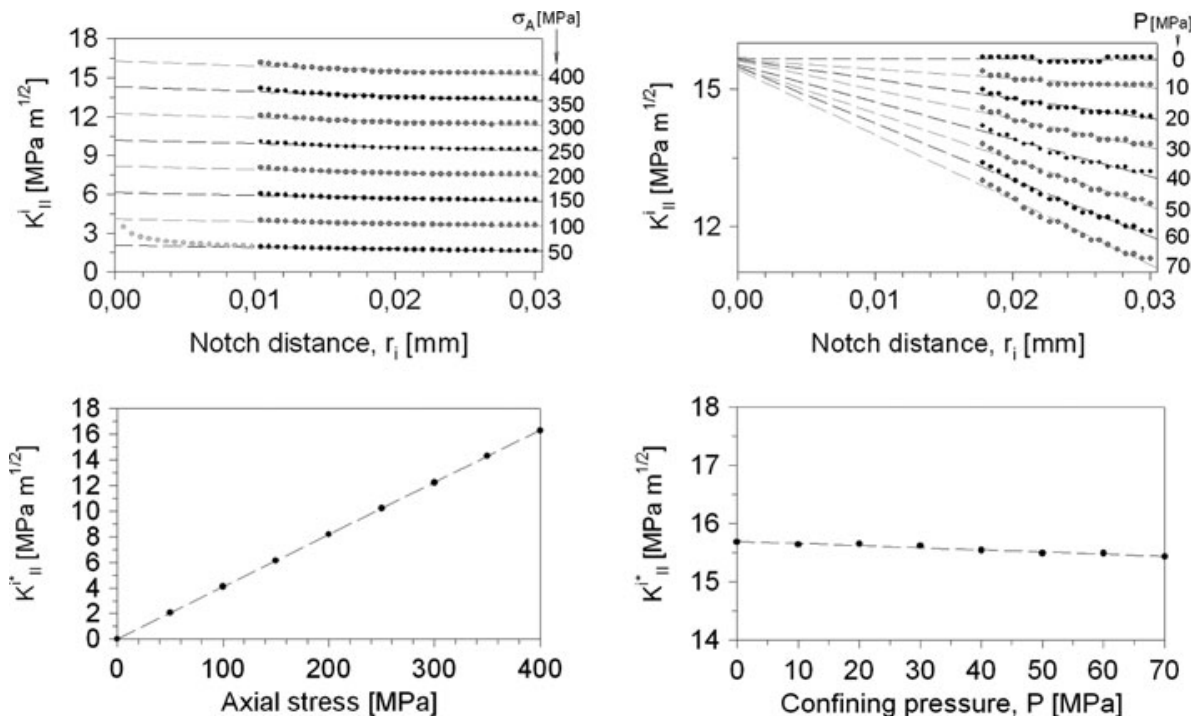

Some other methods can be used to evaluate $K_{\text {IIC }}$ from the PTS/CP experiment; some of those are explained and discussed in Backers (2005). Here, the values obtained by the DET method used here are compared to the $J$-integral approach (Rice 1968). In the case of the PTS/CP method it becomes

$J \approx \frac{1}{2} \Delta u \Delta \tau$

where $\Delta u$ is the shear displacement in the notch plane and $\Delta \tau$ the drop of average shear stress from peak to residual shear stress across the fracture faces. $\Delta u$ and $\Delta \tau$ can be obtained from the post peak part of the shear stress versus strain diagram (see Hakami 1988 for details).

The Energy Release rate obtained by the $J$-integral analysis of a limestone sample $\left(P_{C}=5 \mathrm{MPa}, \sigma_{\mathrm{A}}=\right.$ $87.2 \mathrm{MPa}$ ) is $J \approx 4 \times 10^{4} \mathrm{~J} / \mathrm{m}^{2}$ or $K_{\mathrm{IIC}} \approx 3.1 \mathrm{MPa} \mathrm{m}^{1 / 2}$. In comparison, the DET method provides $K_{\text {IIC }}=3.3$ $\mathrm{MPa} \mathrm{m}^{1 / 2}$. The J-integral method requires that small scale yielding is evident to be able to assume equivalence to $K_{\text {IIC }}$, and additional fracturing in the specimens, as sometimes obtained, limits the evaluation capability of the method.

The advantage of the suggested method to determine $K_{\text {IIC }}$ is that only the peak load needs to be recorded. For e.g., a $J$-integral approach a full load and displacement recording would be necessary.

The given formulation is valid only for the suggested geometry and deviations from the ideal configuration will result in inaccurate values of $K_{\text {IIC }}$. Further, at low confining pressures wing fractures may be introduced in the specimen altering the stress fields. This alteration is not accounted for in the equation.

\subsection{Influence of Confining Pressure}

The shear stress $\left(\tau=F_{\max }(\pi \times \mathrm{ID} \times \mathrm{IP})^{-1}\right)$ (intact rock portion $I P=L-a-b)$ at failure is reported to increase with confining pressure for various rock types. Figure 5 summarises selected data from Backers (2005) and Backers et al. (2002b). The PTS/CP test data shows results for 

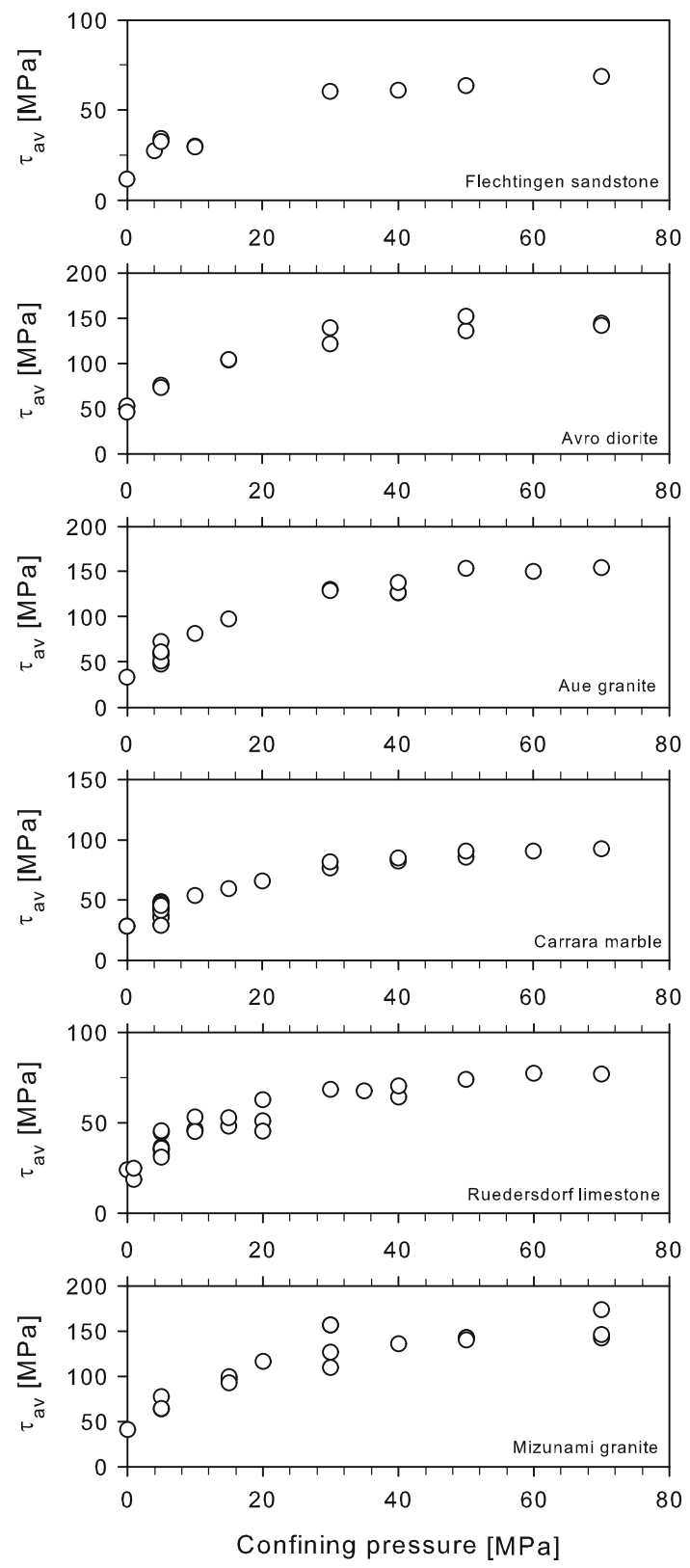

Fig. 5 Influence of confining pressure, $P_{\mathrm{C}}$, on and $\tau_{\mathrm{av}}$ (the shear stress is not an interpreted value and therefore presented here. $K_{\text {IIC }}$ and $\tau_{\text {av }}$ are linked by a factor only and hence the trends are the same), $\tau=F_{\max }(\pi \times \mathrm{ID} \times \mathrm{IP})^{-1}$, for different rock types. (Recalculated data after Backers 2005; Backers et al. 2002b)

experiments performed at confining pressures, $P_{C}$, up to $70 \mathrm{MPa}$.

The reported shear stress at failure increases non-linearly with confining pressure. As $K_{\text {IIC }}$ is linearly linked to the shear stress at failure, ${ }^{1} K_{\text {IIC }}$ shows similar behaviour. Due to the observations from microstructural analyses

\footnotetext{
${ }^{1} K_{\mathrm{IIC}}=7.74 \times 10^{-2} \quad F_{\max }-1.80 \times 10^{-3} \quad P_{\mathrm{C}}=7.74 \times 10^{-2}$ $\tau \times \pi \times \mathrm{ID} \times \mathrm{IP}-1.80 \times 10^{-3} P_{\mathrm{C}}$.
}

(Backers et al. 2002a), the increase of shear stress and fracture toughness may be interpreted as a bi-linear relation. At low confining pressures the average shear stress between the notches, $\tau_{\mathrm{av}}$, steeply increases with $P_{C}$, while at high $P_{C}$ the $\tau_{\mathrm{av}}$ necessary for fracture propagation increases moderately with increase in confining pressure. The transition from steep to shallow slope is around 25-35 MPa. Alternatively, one might consider a square root rise to a maximum value. However, that would imply constant fracture toughness at very high $P_{\mathrm{C}}$ and no frictional influence.

From microstructural analyses, it has been reported that at low confining pressures wing fractures, i.e. tensile fractures, are initiated at the bottom notch inner tip at about $30 \%$ of the peak load. The wing fractures are typically not initiated at confining pressures $P_{\mathrm{C}}>30 \mathrm{MPa}$. Also, the signature (shape and crack content) of the fracture process zone changes with the increase of confining pressure up to about $30 \mathrm{MPa}$, but not above, indicating a change of micromechanism. A discussion of these features can be found in Backers et al. (2002a, b).

\subsection{Discussion of Loading History}

The PTS/CP experiment has the unique ability to independently apply an external shear load and a normal stress perpendicular to the plane of shear loading. In principle, some other methods do have the possibility to vary the confining pressure, but not independently to an external shear load (i.e. triaxial compression test (Hakami and Stephansson 1990) and compression shear cube test (Jumikis 1979). The very important influence of overall compression (confinement) on Mode II loading induced fracturing (Melin 1986; Lawn 1993) can be adequately studied by the Punch-Through Shear test only.

Due to the geometry and the suggested loading layout of the test, the specimen is not loaded purely isostatically on application of the confining pressure. A shear load is introduced in the plane between the notches. The ratio of confining pressure to shear stress, $\kappa=P_{\mathrm{C}} / \tau$, is constant during application of confining pressure.

After application of confining pressure, the inner cylinder is punched down in displacement control. The ratio of confining pressure to shear stress, $\kappa=P_{\mathrm{C}} \tau$, will, therefore, decrease on punching down the inner cylinder. It was shown numerically by Melin (1986) that at high ratios of $\kappa$ Mode II is preferred. Lower ratios will cause preferred initiation of Mode I fracture. When $P_{\mathrm{C}}$ is high enough $K_{\text {II }}$ will reach $K_{\text {IIC }}$ before $\tau$ has reached the level at which Mode I is preferred. $\kappa$ is decreased in the PTS/CP experimental procedure, hence Mode II is preferred if $P_{\mathrm{C}}$ is sufficiently high. In other methods (e.g. Rao et al. 2003; Jumikis 1979), Mode II loading is applied by adjusting the loading angle and 
confining pressure also depends on the loading angle. Hence, $\kappa$ is governed by the limited loading angle to achieve Mode II loading and then is kept constant with simultaneous increase of shear stress and confining pressure.

\subsection{Discussion of Displacement Rate}

It has been shown for a selection of rock types that the displacement rate has minor influence on the peak strength Backers 2005). In a testing series the displacement rate was varied between $3.3 \times 10^{-7}$ and $1.7 \times 10^{-3} \mathrm{~m} / \mathrm{s}$ at constant confining pressure for various rock types (Fig. 6). The tested rock types have homogeneous mineralogical composition and grain size. For an inhomogeneous, coarse grained granite it was reported that the fracture initiation stress increases at higher displacement rates. The suggested displacement rate of $3.3 \times 10^{-6} \mathrm{~m} / \mathrm{s}$ allows performance of the test within reasonable time without effects of the operational condition such as subcritical crack growth weakening effects. It should be noted that there is evidence to expect an influence by this subcritical crack growth mechanism on individual rock types, and this possibility should be considered in the planning of a testing campaign (c.f. Sect. 9.8).

\subsection{Discussion of Geometry}

The circular geometry of the PTS/CP experiment is superior to a rectangular geometry in terms of structural
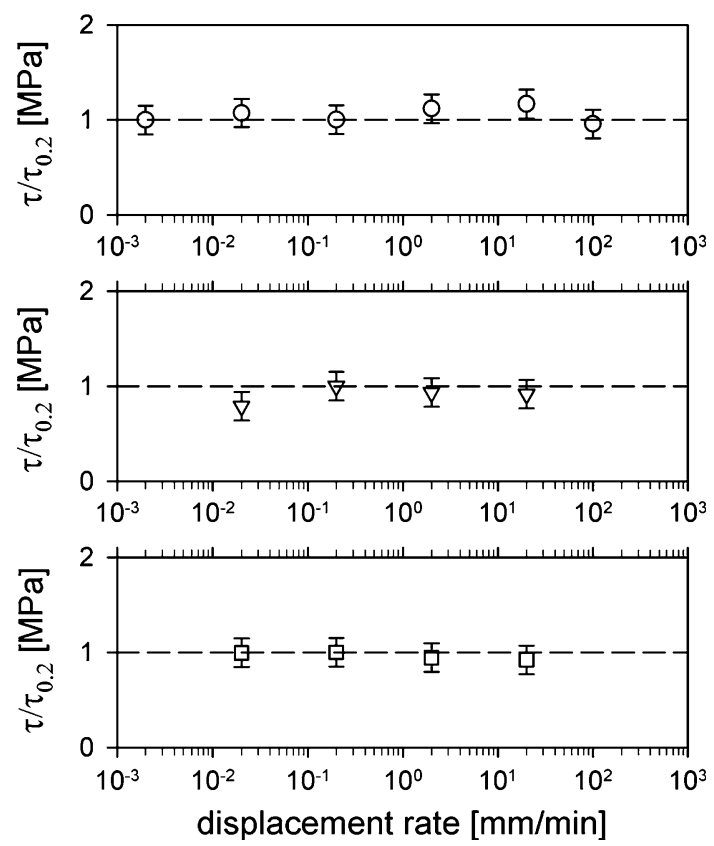

Fig. 6 Shear stress on notch plane at fracture initiation versus displacement rate at constant confining pressure of $5 \mathrm{MPa}$ for a selection of rock types [the shear stress at fracture initiation is normalised with the shear stress at $0.2 \mathrm{~mm} / \mathrm{min}$. Top Carrara marble; middle Flechtingen sandstone; bottom Ruedersdorf limestone] stability as is mostly favoured in several Mode II testing methods. The tubular (hollow-cylindrical) layout of the $\mathrm{PTS} / \mathrm{CP}$ test in the notch regions is able to withstand high confining pressures due to the tangential stresses; no sign of specimen failure is reported up to $120 \mathrm{MPa}$ for limestone (Backers et al. 2004). A geometry with straight notches can be studied at low confining pressures only, as bending stresses introduced by the confining pressure would cause failure.

\subsubsection{Influence of Notch Depth}

Variation of the notch depth yielded a region of constant shear stress in the plane between the notches for $10 \mathrm{~mm}<\mathrm{IP}<20 \mathrm{~mm}$ (Fig. 7). The upper notch depth, $a$, is fixed to $5 \mathrm{~mm}$ at specimen height $L=50 \mathrm{~mm}$ and the lower notch depth, $b$, is varied. The average shear stress on the cylindrical plane between the notches remains almost constant for Ruedersdorf limestone and Carrara marble, but increases for small IP for Aue granite. It is constant between IPs of approximately 10 and $20 \mathrm{~mm}$ for the three rock types. The suggested IP of $15 \mathrm{~mm}$ lies within the constant regime for all tested rock types.

Variation of rock ligament between the notches, IP, illustrates a plateau of $\tau_{\text {av }}$ for a certain range of IP (Fig. 7). Similar results are reported by Yoon et al. (Yoon and Jeon

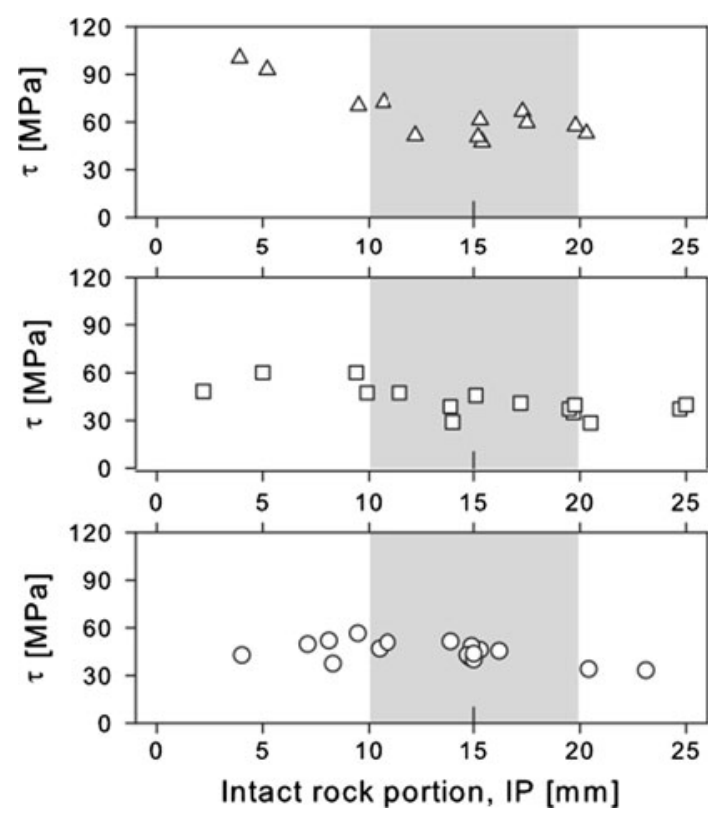

Fig. 7 Shear stress on notch plane at fracture initiation versus intact rock portion IP [The average shear stress on the cylindrical plane between the notches remains almost constant for Ruedersdorf limestone and Carrara marble, but increases for small IP for Aue granite. It is constant between IPs of approximately 10 and $20 \mathrm{~mm}$ for the three rock types. $(L=50 \mathrm{~mm}, D=50 \mathrm{~mm}, a \approx 5 \mathrm{~mm}$, $\left.P_{\mathrm{C}}=5 \mathrm{MPa}\right)$. Top Aue granite; middle Ruedersdorf limestone; bottom Carrara marble. Recalculated data from Backers (2005)] 
2003) for Daejeon granite. They report constant $K_{\text {IIC }}$ for IP of about 17 to $40 \mathrm{~mm}$. Numerical analyses performed by Watkins (1983) on samples with similar, but cubic geometry give evidence of constant stress intensity factor in Mode II for IP/ $L$ ratios of $0.3-0.5$ (IP $=15-25 \mathrm{~mm}$ in case of PTS/CP geometry) for experimental Mode II fracture toughness determination of mortar without confining pressure.

For small ligament lengths the notches are expected to influence each other by coalescence and interaction of the initial process zones before actual fracture propagation takes place at peak load; a decrease of shear stress necessary for fracture propagation is expected at small IP. The initial fracture process zone was shown by means of acoustic emission to be few millimetres in length ( 2-3 mm for Mizunami granite; (Backers 2005; Stanchits et al. 2003). If the process zones of the top and bottom notches interact at low IP, as is suggested by acoustic emission, coalescence/overlap of the fracture process zones should result in a magnified loss of strength. This is only vaguely supported by the shape of the stress versus IP plot at low IP in Fig. 7 for Ruedersdorf limestone and Carrara marble. The elevated average shear stress necessary for fracture growth in Aue granite (Fig. 7) might be explained by the comparably large grains (average is $1 \mathrm{~mm}$, but up to $5 \mathrm{~mm}$ are included). At small IP only few grains are located between the notches and hence coalescence might be aggravated by inter- as well as intragranular crack propagation accompanied by interlocking and crack arrest.

\subsubsection{Influence of Asymmetric Specimen Geometry}

The proposed depth of the notches is non-symmetrical; this is to avoid compressive failure of the upper part of the inner cylinder during axial loading.

To verify an influence of the asymmetry on the test results, tests on samples of $L=25 \mathrm{~mm}$ with $a=b=5$ $\mathrm{mm}$, that is, with a similar length of IP as for the suggested geometry, are performed. $\tau_{\text {av }}$ is the same within sample-tosample scatter for both the suggested $(L=50 \mathrm{~mm})$ and short ( $L=25 \mathrm{~mm}$ ) geometries (Fig. 8). This also suggests that samples of $L=25 \mathrm{~mm}$ may be used if sample material is slender. Nevertheless, larger specimens are easier to handle and specimen preparation is more secure.

To investigate the influence of notch length, tests were performed with $a=30 \mathrm{~mm}$ and $b=5 \mathrm{~mm}$, i.e. with the (suggested) specimen turned upside down, and compared to testing of samples with suggested set-up (Fig. 8). No evidence for a noteworthy influence of the notch depth on $\tau_{\mathrm{av}}$ is reported (Backers 2005). During this series of testing, compressive failure of the top of the inner cylinder was frequently observed for specimens with $a=30 \mathrm{~mm}$. (a)

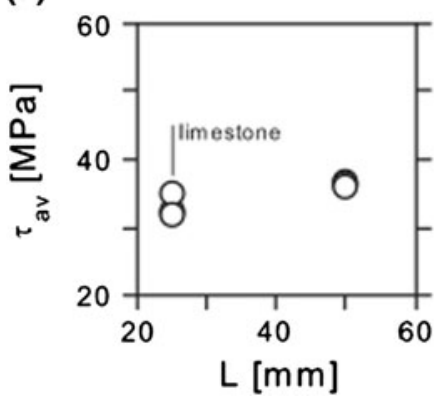

(b)

Fig. 8 a Influence of symmetrical and unsymmetrical sample geometry. $\tau_{\text {av }}$ is similar for symmetrical $(L=25 \mathrm{~mm})$ and unsymmetrical $(L=50 \mathrm{~mm})$ Ruedersdorf limestone samples. $(a=5 \mathrm{~mm}, D=$ $50 \mathrm{~mm}, P_{\mathrm{C}}=5 \mathrm{MPa}$ ). $\mathbf{b}$ Influence of the upper notch length, $a$, on $\tau_{\mathrm{av}}$ of Carrara marble and Ruedersdorf limestone (white circles) and Carrara marble (grey circles). [Results for upper notch depth $a=5$ and $30 \mathrm{~mm}$ with similar IP are given. There is no evidence for a significant influence of the notch depth on $\tau_{\mathrm{av}}$. $(L=50 \mathrm{~mm}, D=50$ $\left.\mathrm{mm}, P_{\mathrm{C}}=5 \mathrm{MPa}\right)$. Recalculated data from Backers (2005)]

An unsymmetrical shape of the sample, i.e. notch depth $a \neq b$, and sample height, $L$, is shown to have a minor influence on the obtained $\tau_{\mathrm{av}}$. Hence, the contribution of bending of the unsupported outer ring to the Mode II fracture process is either negligible or non-existing.

\subsubsection{Influence of Notch Diameter and Sample Diameter}

It should be noted that the Mode II fracture toughness as derived from the PTS/CP experiment may be sensitive to the sample diameter $D$ and notch diameter $I D$ (Backers 2005). It was reported that $\tau_{\mathrm{av}}$ decreases with increasing ID at constant $D$ for one large grained rock type. In addition, from selected experiments it is suggested that an increase of $D$ increases $\tau_{\mathrm{av}}$ at given ID. The effect appears to depend on grain size, but has only been studied at low confining pressure up to $P_{\mathrm{C}}=5 \mathrm{MPa}$.

\subsubsection{Influence of Notch Width}

Experiments with notch widths, $t$, of $0.8,1.5$ and $3.0 \mathrm{~mm}$ were carried out on Carrara marble (Backers 2005). The $0.8 \mathrm{~mm}$ notch was manufactured using a CNC milling machine, the $1.5 \mathrm{~mm}$ notch was prepared using a standard drill bit, and the $3.0 \mathrm{~mm}$ notch was created by two drill bits with overlapping diameters. Results from this series of experiments are given in Fig. 9. The differences in $\tau_{\mathrm{av}}$ show no clear trend for the tested $t$. Slight variation of $\tau_{\mathrm{av}}$ may apply due to the different methods to introduce the notches. Further, in a wider notch more grains are intersected at the bottommost of the notch, and hence more grain boundaries might be preferably oriented for local failure. The notch width $(t=1.5 \mathrm{~mm})$ for the method was 


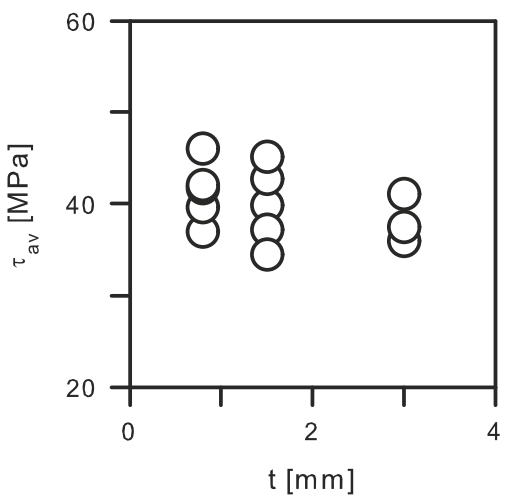

Fig. 9 Influence of the notch width, $t$, on $\tau_{\text {av }}$ for Carrara marble. [The shear stress at failure remains similar for the tested $t$. $(L=50 \mathrm{~mm}$, $D=50 \mathrm{~mm}, a \approx 5 \mathrm{~mm}$, ID $\approx 25 \mathrm{~mm}$, IP $\approx 15 \mathrm{~mm}$ ). Reprocessed data from Backers (2005)]

recommended as it may be produced with conventional hollow drill bits.

\subsection{Discussion of Fracture Generation}

The fracture generation was studied on a variety of specimens and rock types and under varying boundary conditions. Fracture development and characteristics were described using macroscopic observations, thin section analysis, SEM, and analysis of acoustic emission recordings.

Figure 10 summarises the typical fracture characteristics as observed in several studies. At low confining pressures, typically $P_{\mathrm{C}}<30 \mathrm{MPa}$, at about $30 \%$ of the peak load a wing shaped fracture develops from the bottom notch inner tip (Fig. 10a). During propagation it turns towards the centre of the specimen until it is oriented almost vertically and then stops. Frequently, it stops even before aligning itself parallel to the displacement direction. The length of the wing fracture decreases with increasing confining pressure. At about $60 \%$ of the peak load at the top notch a fracture was frequently observed propagating from the dilatant tip of the notch to the mantle surface of the specimen (Fig. 10b). Upon further loading these fractures remain stable. At peak load a fracture starts from the bottom notch and propagates to connect to the top notch (Fig. 10c). At fracture propagation the load versus displacement data shows negative slope indicating disintegration.

The reported formation of the bottom wing fracture ( $\sim 30 \%$ peak load) and upper horizontal fracture ( $\sim 60 \%$ peak load) are not detectable in the stress versus displacement data, hence the energy consumption of those is assumed to be minor.

Increased confining pressure, typically $P_{\mathrm{C}}>30 \mathrm{MPa}$, the wing shaped fractures are not initiated. The negative stress intensity at the level of loading is sufficient to suppress tensile macroscopic fracture. Only the fracture connecting the notches develops at increased confining pressures.

In contrast to the wing shaped fracture, which is usually a very distinct feature highlighting only a single crack line separating mostly grains boundaries, the fracture that (a)
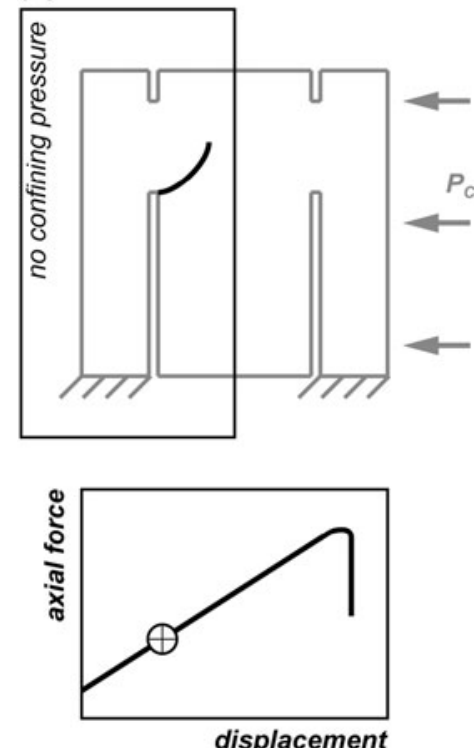

(b)
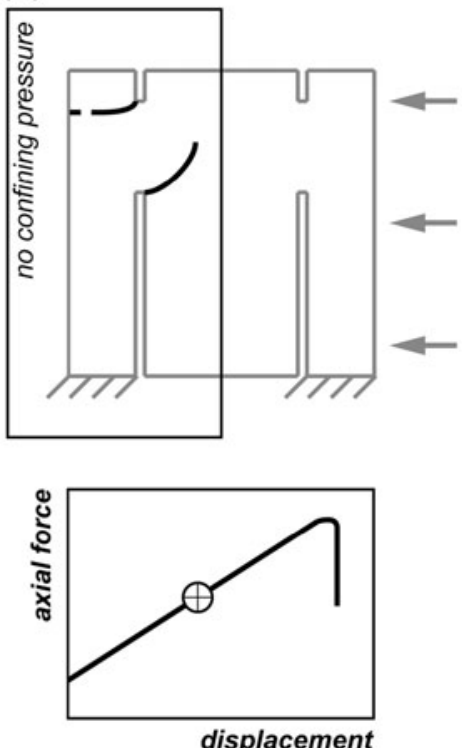

(c)
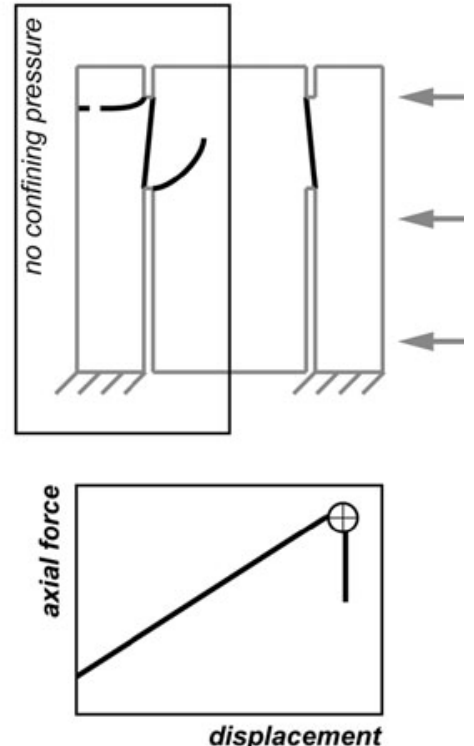

Fig. 10 Fracture evolution in the PTS/CP experiment. Top fracture evolution for $P_{\mathrm{C}}=0.1 \mathrm{MPa}$ (left side of individual sketch) and $P_{\mathrm{C}}>30 \mathrm{MPa}$ (right side of individual sketch). [The axial force vs. displacement data is given at the bottom and displays the position of the top drawings in the loading path. a $30 \%$ of peak load, b $60 \%$ of peak load, c peak load] 
develops at peak load shows a wide fracture process zone. In a study of the influence of the confining pressure on the characteristic of the process zone of the shear fracture it was observed that the width of the zone is considerably reduced with increase of confining pressure (Backers et al. 2002a). The applied normal load to the fracture trace alters the local stress redistribution and the fractures initiated in the process zone rotate to align with the main fracture trace. Further, less crack surface is initiated leading to a smaller fracture process zone width. These changes in characteristics were most prominent at $P_{\mathrm{C}}<30 \mathrm{MPa}$. Above this confining pressure the reported changes were minor.

The changes in appearance of the fracture evolution and its characteristics with confining pressure may be related to a change in slope in the shear strength/Mode II fracture toughness vs confining pressure data, c.f. Fig. 5.

Application of confining pressure superimposes a negative $^{2} K_{\mathrm{I}}$ and this results in shorter wing fractures that stop before being aligned with the major principle stress. No wing fractures are initiated at the notches in samples subjected to confining pressures $>30 \mathrm{MPa}$. According to Melin (1986) pure macroscopic shear fracture growth occurs if the level of confining pressure is high enough so that all tensile stresses at the fracture tips vanish or even become compressive. The stresses at the bottom notch in PTS/CP testing at higher confining pressures are consequently below a critical level to allow macroscopic wing fracture initiation. Suppression of Mode I fracturing above a certain level of confining pressure was experimentally proven by Bobet and Einstein (1998) and is consistent with the observations for the PTS/CP experiment.

\subsection{Influence of Temperature}

In a series of experiments on a Korean granite the influence of temperature on Mode II fracture toughness was studied by Meier et al. (2009). 53 specimens were tested at temperatures ranging from -75 to $250{ }^{\circ} \mathrm{C}$ and using the Punch-Through Shear with Confining Pressure experiment (Fig. 11). Variation of temperature has an impact upon the average shear strength granite within the applied temperature range. The shear stress at failure shows elevated values at sub-zero temperatures; it is anticipated that the water phase of the air dry specimens forms ice and the toughness of the ice adds to the toughness of the rock. As the water is frozen below $0{ }^{\circ} \mathrm{C}$ and the properties do not vary significantly, and $\tau_{\mathrm{av}}$ remains constant for that interval, the hypothesis of the superposition of rock and ice toughness is assumed valid. Around the freezing point the values drop down to remain constant for up to $100{ }^{\circ} \mathrm{C}$.

\footnotetext{
${ }^{2}$ A negative $K_{\mathrm{I}}$ describes a state of compression.
}

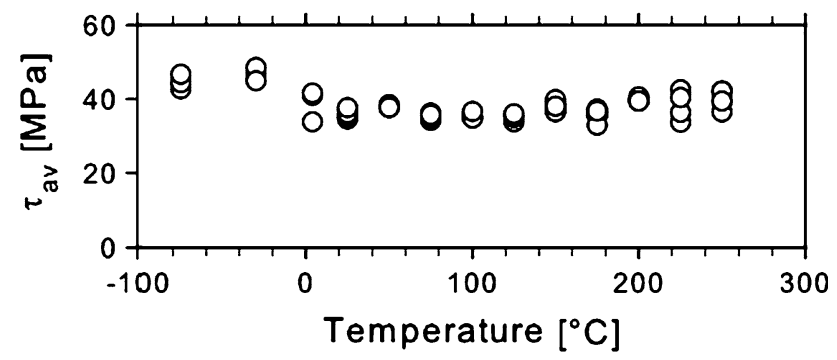

Fig. $11 \tau_{\text {av }}$ at different temperatures at ambient pressure conditions $\left(P_{\mathrm{C}}=0.1 \mathrm{MPa}\right)$ for a Korean granite

Presumably above temperatures of $100{ }^{\circ} \mathrm{C} \tau_{\mathrm{av}}$ is slightly increasing again; the increase is due to crack propagation into newly formed arrester positions (i.e. microcracks in orthogonal directions to the main travel direction).

\subsection{Subcritical Crack Growth}

The PTS/CP experiment was also employed to determine the subcritical crack growth parameters as defined in Charles' law (Backers et al. 2006). The study applied static loading at different fractions of the peak load and measured the time-to-failure. From a weakest link theory (Wilkins 1980, 1987) the subcritical parameters may be derived.

Acknowledgments Erik Rybacki, Georg Dresen (both HelmholtzCentre Potsdam-GFZ German Research Centre for Geosciences, Germany) and Tobias Meier (then Geomecon $\mathrm{GmbH}$ ) were involved in certain aspects of the development of the testing procedure, the discussion of results, and the review of this contribution. John Napier, John Kemeny, Chulwhan Park, Resat Ulusay and an anonymous reviewer gave valuable comments, which helped improve the manuscript. The early versions of the method were developed in collaboration with Technical University of Berlin, Germany, and Royal Institute of Technology KTH Stockholm, Sweden. The main body of work was conducted at Helmholtz-Centre Potsdam-GFZ German Research Centre for Geosciences, Germany. The work on some aspects as reported in the appendix was carried out partly in the context of a GeoFrames $\mathrm{GmbH}$ (now Geomecon $\mathrm{GmbH}$ ) research and development project supported by the European Union, European Fund for Regional Development, program 'Investment to Future', Period 2007-2013. Calvin Seward (Geomecon GmbH) gave the manuscript a final language reading. The contributions of the different individuals and institutions are greatly acknowledged.

\section{References}

Backers T (2005) Fracture toughness determination and micromechanics of rock under mode I and mode II loading. University of Potsdam, Potsdam

Backers $\mathrm{T}$ et al (2002a) Fractography of rock from the new punchthrough shear test, in structural integrity and fracture. In: Dyskin $\mathrm{AV}, \mathrm{Hu} \mathrm{X}$, Sahouryeh E (eds) The International Conference on structural integrity and fracture, Perth, Australia

Backers T, Stephansson O, Rybacki E (2002b) Rock fracture toughness testing in Mode II-punch-through shear test. Int J Rock Mech Min Sci 39(6):755-769 
Backers T et al (2004) New data on Mode II fracture toughness of rock from the punch-through shear test. Int J Rock Mech Min Sci 41(3):351-352

Backers T, Stanchits S, Dresen G (2005) Tensile fracture propagation and acoustic emission activity in sandstone: the effect of loading rate. Int J Rock Mech Min Sci 42(7-8):1094-1101

Backers T, Antikainen J, Rinne M (2006) Time dependent fracture growth in intact crystalline rock: laboratory procedures and results. In: GeoProc2006-2nd International Conference on coupled T-H-M-C processes in geosystems: fundamentals, modelling, experiments, applications, Nanjing, China

Bobet A, Einstein HH (1998) Fracture coalescence in rock-type materials under uniaxial and biaxial compression. Int $\mathrm{J}$ Rock Mech Min Sci 35(7):863-888

Chang SH, Lee CI, Jeon S (2002) Measurement of rock fracture toughness under modes I and II and mixed-mode conditions by using disc-type specimens. Eng Geol 66(1-2):79-97

Dyskin AV (1999) On the role of stress fluctuations in brittle fracture. Int J Fract 100(1):29-53

Fowell RJ et al (1995) Suggested method for determining Mode-I fracture-toughness using cracked chevron-notched Brazilian disc (Ccnbd) specimens. Int J Rock Mech Min Sci Geomech Abstr 32(1):57-64

Hakami H (1988) Post-failure behaviour of brittle rock. Division of Rock Mechanics, Lulea University of Technology, Sweden

Hakami H, Stephansson O (1990) Shear fracture energy of Stripa granite-results of controlled triaxial testing. Eng Fract Mech $35: 855-865$

Jumikis AR (1979) Rock Mechanics. Trans Tech Publications (series on rock and soil mechanics), Clausthal, p 356. ISBN:0878490264

Ko TY, Kemeny J (2006) Determination of Mode II stress intensity factor using short beam compression test. In: 4th Asian Rock Mechanics Symposium, Singapore

Lawn BR (1993) Fracture of Brittle Solids. Cambridge Univiversity Press, Cambridge

Lee JS (2007) Time-dependent crack growth in brittle rocks and field applictions to geological hazards. The University of Arizona, USA

Lim IL, Johnston IW, Choi SK (1993) Stress Intensity Factors for Semicircular Specimens under 3-Point Bending. Eng Fract Mech 44(3):363-382
Meier T, Backers T, Stephansson O (2009) The influence of temperature on Mode II fracture toughness using the PunchThrough Shear with Confining Pressure experiment. In: Diederichs M, Grasselli G (eds) ROCKENG09: Proceedings of the 3rd CANUS Rock Mechanics Symposium, Toronto, Canada

Melin S (1986) When does a crack grow under mode II conditions? Int J Fract 30:103-114

Ouchterlony F (1988) Suggested Methods for Determining the Fracture Toughness of Rock. Int J Rock Mech Min Sci Geomech Abstr 25(2):71-96

Rao QH et al (2003) Shear fracture (Mode II) of brittle rock. Int J Rock Mech Min Sci 40(3):355-375

Rice JR (1968) A path independent integral and the approximate analysis of strain concentration by notches and cracks. J Appl Mech 35:379-386

Stanchits S et al (2003) Comparison of acoustic emission events and micromechanics of granite under Mode I and Mode II loading. In: Makurat A, Curri P (eds) EUROConference on rock physics and geomechanics-micromechanics, flow and chemical reactions. Delft, The Netherlands

Szwedzicki T (2003) Quality assurance in mine ground control management. Int J Rock Mech Min Sci 40(4):565-572

Watkins J (1983) Fracture toughness test for soll-cement samples in mode II. Int J Fract 23(4):R135-R138

Watkins J, Liu KLW (1985) A finite element study of the short beam test specimen under mode II loading. Int $\mathrm{J}$ Cem Compos Lightweight Concrete 7(1):39-47

Whittaker BN, Singh RN, Sun G (1992) Rock fracture mechanicsprinciples, design and applications. Elsevier Science Publisher, Amsterdam

Wilkins BJS (1980) Slow crack growth and delayed failure of granite. Int J Rock Mech Min Sci Geomech Abstr 17(6):365-369

Wilkins BJS (1987) The long-term strength of plutonic rock. Int J Rock Mech Min Sci Geomech Abstr 24(6):379-380

Yoon J, Jeon S (2003) An experimental study on Mode II fracture toughness determination of rock. J Korean Soc Rock Mech 13(1):64-75 